\title{
A new electrocardiographic parameter associated with sudden cardiac death in pulmonary sarcoidosis
}

Samim Emet ${ }^{1}$, Seda T. Onur², Sinem N. Sokucu², Senay Aydin², Levent Dalar², Erdogan Cetinkaya², Imran Onur ${ }^{1}$

${ }^{1}$ Department of Cardiology, Faculty of Medicine, Istanbul University, Istanbul, Turkey ${ }^{2}$ Yedikule Chest Disease Training and Research Hospital, Istanbul, Turkey

Submitted: 29 December 2018

Accepted: 21 May 2019

Arch Med Sci 2020; 16 (3): 559-568

DOI: https://doi.org/10.5114/aoms.2019.88393

Copyright $\odot 2019$ Termedia \& Banach

\section{Abstract}

Introduction: The interval from the peak to the end of the electrocardiographic $T$ wave $\left(T_{-}-T_{e}\right)$ may correspond to malignant ventricular arrhythmias. In this study we aimed to assess $T_{p}-T_{e}$ variability and investigate the transmural dispersion of repolarisation in pulmonary sarcoidosis disease without proofed cardiac involvement.

Material and methods: This was a retrospective case-control study that included patients who had a pathologic and radiologic diagnosis of sarcoidosis. All data of the patients' demographic features and electrocardiographs were analysed.

Results: We enrolled 78 patients with sarcoidosis and 54 healthy volunteers as controls in our study. Men comprised $36 \%$ of the sarcoidosis group and $27 \%$ of controls. The mean age in the sarcoidosis and control group was $45.4 \pm 8.7$ years (range: $23-58$ years) and $44.6 \pm 11.9$ years (range: $21-73$ years), respectively. There was no significant difference between the groups for age or sex ( $p=0.654, p=0.246$, respectively). There was a significant increase in $T_{p}-T_{e}$ results in all precordial leads in the sarcoidosis group compared with the control group $(p<0.05)$.

Conclusions: Pulmonary sarcoidosis is suspected to have cardiac involvement; therefore, we need to develop new approaches. We present strong evidence that $T_{p}-T_{e}$ intervals were increased in patients with pulmonary sarcoidosis, which suggests that there may be a link between sarcoidosis and ventricular arrhythmias without proofed cardiac involvement.

Key words: sarcoidosis, ventricular arrhythmia, $T_{p}-T_{e}$ interval, cardiac involvement.

\section{Introduction}

Sarcoidosis is a multisystem disorder of unknown aetiology characterised by infiltration of numerous organs by noncaseating granulomas. The organs that are most affected by this disease are lungs, lymph nodes, skin, and eyes. The Case-Control Aetiologic Study of Sarcoidosis (ACCESS) study showed that its prevalence may change among different populations. The clinical presentation, frequency, and severity level of the disease can also vary among different races and study populations [1-3]. The highest annual incidence of sarcoidosis has been observed in northern European countries (5 to 40 cases per 100,000 people) [4]. Extrapulmonary involvement of sarcoidosis is known to be affected by genetic factors, and its rate in Turkey is $2.2 \%$ [5].

\author{
Corresponding author: \\ Samim Emet \\ Department of Cardiology \\ Faculty of Medicine \\ Istanbul University \\ Millet St. \\ 34390 Capa/Istanbul \\ Turkey \\ E-mail: \\ samim03@hotmail.com
}


Approximately $5 \%$ of patients with sarcoidosis will have clinically manifest cardiac involvement and another $20-25 \%$ have asymptomatic cardiac involvement (clinically silent disease) [6, 7], and in $20-30 \%$ of cases in pathology series [7-10]. Myocardial infiltration, which results in cardiac sarcoidosis, is responsible for $50 \%$ of deaths of patients with sarcoidosis $[8,9]$. It is a common and serious kind of infiltration when there are clinical and/or electrical signs of disease [7, 10]. Cardiac infiltration is frequently characterised by intraventricular septum and/or the left ventricle $[7,10]$. The existence of large numbers of lymphocytes at the border zones around granulomas can be observed in pathologic samples of myocardium involved with sarcoidosis. Clinical proof of myocardial involvement during the whole life is seen in only $40-50 \%$ of patients with cardiac sarcoidosis at necropsy [11]. Sarcoid granulomas may serve as foci for abnormal automaticity or to disperse both ventricular activation and recovery processes that can cause reentrant tachycardia. The reentrant pathway could be related to the healing of cardiac granulomas in the inactive phase of the disease, or it could be the result of active granulomatous inflammation. Electrocardiography (ECG) is often nondiagnostic or nonspecific even though it is an important part of patient evaluation. The American Thoracic Society (ATS) recommended initial cardiac evaluation of patients with sarcoidosis is ECG, and as such, the only information about cardiac involvement in sarcoidosis is viewed in the $\mathrm{T}_{\mathrm{p}}-\mathrm{T}_{\mathrm{e}}$ interval in ECG screening [1].

According to recent studies, the interval between the peak and the end of $T$ wave on electrocardiogram (ECG), i.e. $T_{p}-T_{e}$ interval, may stand for the index of total (transmural, apicobasal, and global) dispersion of repolarisation [12, 13]. Furthermore, increased $\mathrm{T}_{\mathrm{p}}-\mathrm{T}_{\mathrm{e}}$ interval could be a practical index to estimate cardiovascular mortality and ventricular tachyarrhythmias [14, 15].

The aim of this study was to evaluate repolarisation dispersion obtained from 12-lead surface electrocardiograms (including $\mathrm{T}_{\mathrm{p}}-\mathrm{T}_{\mathrm{e}}$ interval) in patients with pulmonary sarcoidosis without proven cardiac involvement. Increased $T_{p}-T_{e}$ interval could be regarded as a beneficial parameter to estimate ventricular tachyarrhythmia and cardiovascular mortality [16]. Our hypothesis was that $T_{p}-T_{e}$ intervals ascend in patients with sarcoidosis, which may cause arrhythmic events; therefore, early screening would be useful for preventing patients from developing cardiac complications due to sarcoidosis.

\section{Material and methods}

This was a retrospective case-control study comprising patients who had a pathologic and ra- diologic diagnosis of sarcoidosis. All data of the patients' demographic features and laboratory findings were recorded. We retrospectively analysed ECGs that were taken in the assessment after the patients' sarcoidosis was diagnosed. Healthy volunteers were enrolled as a control group.

\section{Study population}

Our research included 78 patients with sarcoidosis and 54 healthy controls. In our study, it was important to determine whether there was a history of tuberculosis, and reactivity was investigated carefully. All patients were in our clinic for follow-up between 2012 and 2014. After eliminating other causes of granulomas like tuberculosis and tularaemia, sarcoidosis was determined if patients had compatible clinical and radiologic findings with histologically proven non-caseating granulomas. A bronchoscopic needle aspiration biopsy of the lymph node, mediastinoscopic lymph node excision, and skin biopsies were used for pathologic diagnosis.

Patients were evaluated using chest radiographs and we enrolled those with extrapulmonary involvements. Chest radiographs were classified using the Scadding scale: 0 - normal chest radiographic findings, I- bilateral hilar adenopathy with normal lung parenchyma, II - bilateral hilar adenopathy with pulmonary infiltrates, III - pulmonary infiltrates without hilar adenopathy, and IV - pulmonary fibrosis/fibrocystic parenchymal changes [4, 17].

We retrospectively evaluated patients' documents and obtained data including blood count and biochemistry tests, which gave information about fasting glucose, urea, creatinine, and cholesterol levels at the time of admission to hospital. The patients were further reviewed, and for a diagnosis of sarcoidosis there had to be no evidence of cardiac sarcoidosis.

Patients were excluded from the study if they had the following: coronary artery disease; chronic renal failure; chronic liver disorders; moderate or severe valvular heart disease; prior pacemaker implantation; congenital heart disease; left ventricular systolic dysfunction on GE Vivid 7 echocardiography (EF < 50\%); recent acute coronary syndrome; anaemia; secondary hypertension; haematological disorders; known malignancy; electrolyte imbalance and bundle branch block; atrioventricular conduction abnormalities on ECG; and ECGs without a clear QT segment. In addition to these, we also excluded those with ST-segment elevation, ST-T changes, T-wave inversion, wide QRS complexes, and ventricular preexcitation.

Our control group consisted of healthy volunteers. They had no disease and their chest radiographs were normal. 


\section{Electrocardiographic measurements}

The 12-lead ECG, Cardioline Ar2100adv, Italy, was recorded on paper at $25 \mathrm{~mm} / \mathrm{s}$ and $10 \mathrm{~mm} / \mathrm{Mv}$ gain at rest in the supine position. All ECGs were scanned and analysed. All QT interval measurements were undertaken manually and by two investigators who were medically qualified. The QRS interval was measured from the beginning of the $\mathrm{Q}$ wave, or in absence of the $\mathrm{Q}$ wave, from the beginning of the $R$ wave to the end of the $S$ wave (to its return to the isoelectric line) [18]. The $T_{p}-T_{e}$ interval was measured from the peak of the $T$ wave to the end of $T$ wave. The end of the T wave was defined as the intersection of the tangent to the downslope of the T wave and the isoelectric line [14]. Leads were excluded if the T wave could not be clearly determined. An average value of three readings was calculated for each lead. Only recordings that had more than eight analysable leads were included in the final analysis.

Using the best available $T$ wave in lead $V_{5}$ (a method that has been already described), previous studies have accepted that precordial leads represent transmural dispersion of repolarisation well, while limb leads give good representation of apical-basal or global spatial dispersion $[19,20]$. If the $\mathrm{V}_{5}$ lead was not suitable for measuring, $\mathrm{V}_{4}$ and $\mathrm{V}_{6}$ were used instead [20].

\section{Ethical approval}

The Local Ethics Committee approved the study protocol (Approval number: 21014/1812). All procedures performed in studies involving human participants were in accordance with the ethical standards of the institutional and/or national research committee and with the 1964 Helsinki declaration and its later amendments or comparable ethical standards. This article does not contain any studies with human participants or animals performed by any of the authors. Informed consent was obtained from all individual participants included in the study.

\section{Statistical analysis}

For descriptive statistics of the data the mean, standard deviation, median, minimum, maximum, frequency, and ratio values were used. Variables were analysed for the presence of normal distribution using the Kolmogorov-Smirnov test. Quantitative variables were compared using Mann-Whitney $U$ test and independent sample $t$-test was used. $\chi^{2}$ test was used for the analysis of qualitative data, and the Fischer test was used when the $\chi^{2}$ test conditions were not met. The significance level and cut-off value were evaluated using the ROC curve. Statistical analyses were performed using SPSS 22.0.

\section{Results}

Sarcoidosis was seen more commonly in women $(64 \%)$ in the present study. The female/male ratio was 1.75 . There were no significant differences between age and sex in our study and control groups. There were significantly more co-morbidities in the sarcoidosis group than in the control group $(p<0.05)$.

The study population consisted of middle-aged patients, and the mean age was $45.4 \pm 8.7$ years (range: $23-58$ years). The most frequent symptoms were shortness of breath and cough, respectively. The patients' demographics, clinical characteristics, and laboratory findings are given in Table I. According to the chest $\mathrm{X}$-ray results, sarcoidosis disease severity was $26 \%$ stage $0,45 \%$ stage I, $28 \%$ stage II, and $1 \%$ stage III. There was extrapulmonary involvement as skin involvement in 7 (9\%) patients, 2 (3\%) patients had ocular involvement, and neurologic involvement was detected in 2 (3\%) patients.

$T_{p}-T_{e} V_{1}, T_{p}-T_{e} V_{2}, T_{p}-T_{e} V_{3}, T_{p}-T_{e} V_{4}, T_{p}-T_{e} V_{5}$, and $T_{p}-T_{e} V_{6}$ values were significantly higher in patients with sarcoidosis than in controls (Figure 1). A comparative chart of $T_{p}-T_{e}$ values of the sarcoidosis and control group is shown in Figure 1. The laboratory findings of patients with sarcoidosis are shown in Table I. $T_{p}-T_{e} V_{1}, T_{p}-T_{e} V_{2}, T_{p}-T_{e} V_{3}, T_{p}-T_{e}$ $V_{4}, T_{p}-T_{e} V_{5}$, and $T_{p}-T_{e} V_{6}$ values' $R O C$ curves are shown in Figure 2, and cut-off values according to the findings are specified in Table II. Comparison of $T_{p}-T_{e}$ interval between the sarcoidosis and control groups is shown in Table III. $T_{p}-T_{e}$ intervals were significantly higher in all precordial leads (Table III). There was also no significant difference between $T_{p}-T_{e}$ intervals in sarcoidosis patients who had extra-pulmonary involvement and those who had not (Table IV). Correlations between T-wave peak to end interval of chest derivations and pulmonary function tests are shown in Table $\mathrm{V}$. There was a moderate correlation between $\mathrm{FEV}_{1} \%, \mathrm{FVC} \%$, and $\mathrm{T}_{\mathrm{p}}-\mathrm{T}_{\mathrm{e}} \mathrm{V}_{1}(p=0.05$ and $p=0.01$, respectively). There was a moderate correlation between $\mathrm{FEV}_{1} / \mathrm{FVC}$, DLCO/VA and $\mathrm{T}_{\mathrm{p}}-\mathrm{T}_{\mathrm{e}} \mathrm{V}_{2}, \mathrm{~T}_{\mathrm{p}}-\mathrm{T}_{\mathrm{e}} \mathrm{V}_{3}$ $(p=0.001$ and $p=0.03$, respectively). There was also a moderate correlation between DLCO/VA and $T_{p}-T_{e} V_{4}(p=0.001)$. The best cut-off values of $T_{p}-T_{e}$ intervals to predict sarcoidosis and ROC curve analysis of $T_{p}-T_{e}$ intervals are shown in Table VI and Figure 3, respectively.

\section{Discussion}

Cardiac involvement of pulmonary sarcoidosis is clinically occult in most pulmonary sarcoidosis cases. We evaluated the repolarisation dispersion obtained from 12-lead surface electrocardiograms (including $T_{p}-T_{e}$ interval) in patients with pulmo- 

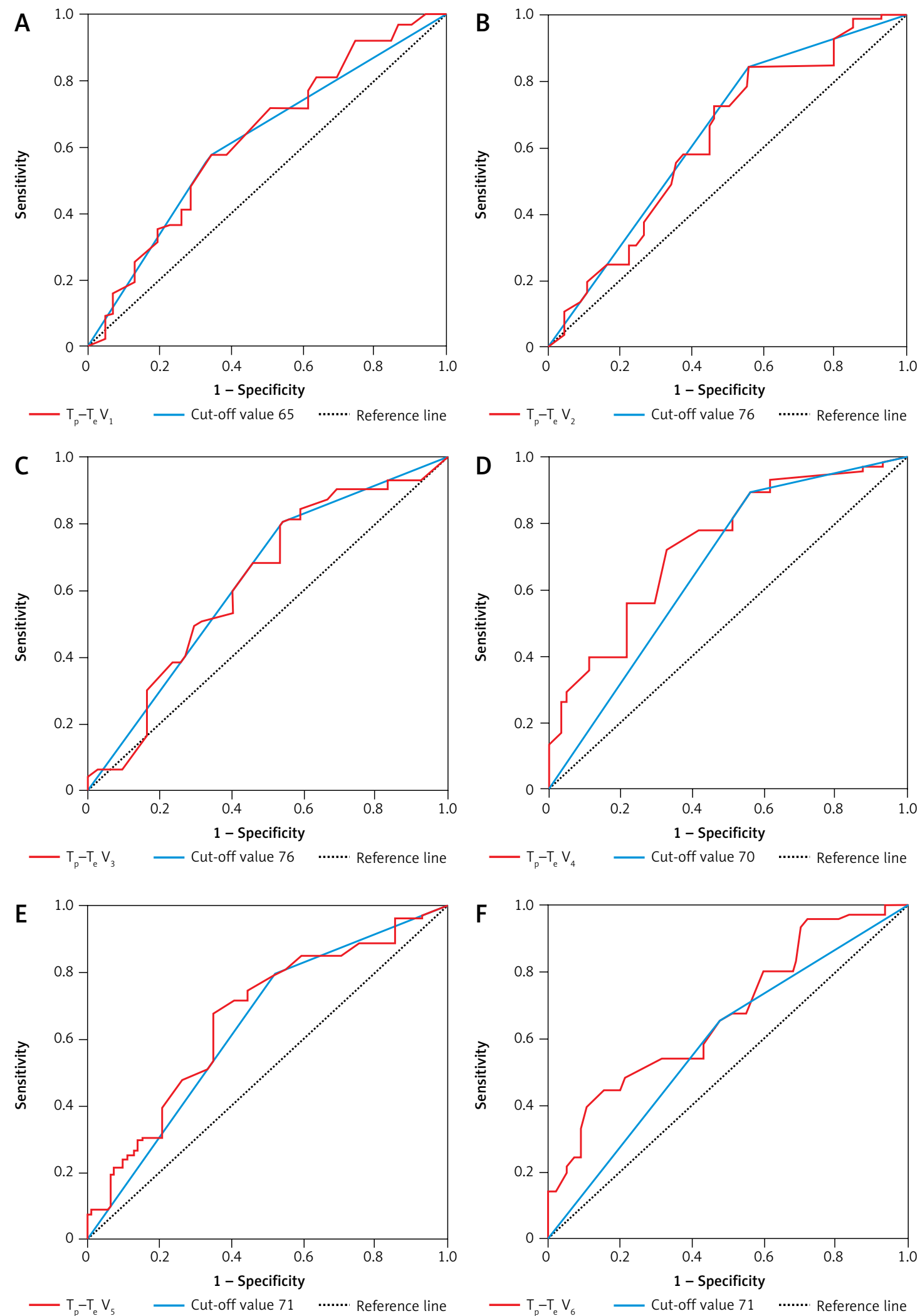

Figure 1. ROC curves of $T_{p}-T_{e}$ values of the chest leads

nary sarcoidosis without proven cardiac involvement. Increased $T_{p}-T_{e}$ interval could be regarded as a beneficial parameter to estimate ventricular tachyarrhythmia and cardiovascular mortality.

Our hypothesis was that $T_{p}-T_{e}$ intervals increase in patients with sarcoidosis, which may cause arrhythmic events; therefore, early screening would be useful to prevent patients from developing 
Table I. Laboratory findings in the sarcoidosis group

\begin{tabular}{|c|c|c|c|}
\hline Parameter & Min.-max. & Median & Mean \pm SD \\
\hline Fasting glucose $[\mathrm{mg} / \mathrm{dl}]$ & $65.0-133.0$ & 93.0 & $94.2 \pm 12.9$ \\
\hline Urea [mg/dl] & $11.0-47.0$ & 28.0 & $29.3 \pm 7.6$ \\
\hline Creatinine $[\mathrm{mg} / \mathrm{dl}]$ & $0.4-1.2$ & 0.7 & $0.7 \pm 0.2$ \\
\hline AST [IU/I] & $11.0-72.0$ & 21.0 & $23.7 \pm 10.5$ \\
\hline ALT [IU/I] & $5.0-102.0$ & 21.0 & $25.7 \pm 18.3$ \\
\hline Total cholesterol [mg/dl] & $126-277$ & 188 & $192.1 \pm 36.8$ \\
\hline Triglycerides [mg/dl] & $43-398$ & 107 & $123.5 \pm 66.7$ \\
\hline $\mathrm{HDL}[\mathrm{mg} / \mathrm{dl}]$ & $27-95$ & 50 & $50.1 \pm 13.1$ \\
\hline LDL [mg/dl] & $73-191$ & 108 & $117.4 \pm 28.8$ \\
\hline $\mathrm{Fe}[\mu \mathrm{g} / \mathrm{dl}]$ & $16-147$ & 61 & $67.1 \pm 29.8$ \\
\hline $\mathrm{HBA}_{1 \mathrm{c}} \%$ & $4.4-7.9$ & 5.9 & $6.0 \pm 0.7$ \\
\hline $\mathrm{T}_{3}[\mathrm{pg} / \mathrm{ml}]$ & $2.4-4.2$ & 3.1 & $3.1 \pm 0.4$ \\
\hline $\mathrm{T}_{4}[\mathrm{ng} / \mathrm{dl}]$ & $0.6-1.2$ & 0.9 & $0.9 \pm 0.1$ \\
\hline TSH [ulU] & $0.4-8.7$ & 1.9 & $2.4 \pm 1.6$ \\
\hline Sedimentation $[\mathrm{mm} / \mathrm{h}]$ & $4.0-52.0$ & 21.0 & $20.6 \pm 12.0$ \\
\hline $\mathrm{WBC}\left[\times 10^{3} / \mathrm{mm}^{3}\right]$ & $3.0-13.5$ & 6.7 & $6.9 \pm 1.8$ \\
\hline $\mathrm{RBC}\left[\times 10^{6} / \mathrm{mm}^{3}\right]$ & $3.8-5.8$ & 4.7 & $4.7 \pm 0.4$ \\
\hline ACE levels [U/I] & $5.3-201.0$ & 48.7 & $59.2 \pm 40.8$ \\
\hline $\mathrm{FEV}_{1} \mathrm{LT}$ & $1.2-5.1$ & 2.4 & $2.5 \pm 0.8$ \\
\hline $\mathrm{FEV}_{1} \%$ pred & $55.0-152.0$ & 88.7 & $90.0 \pm 18.2$ \\
\hline FVC LT & $1.9-6.2$ & 2.9 & $3.2 \pm 0.9$ \\
\hline FVC \% & $51.9-147.0$ & 94.0 & $95.0 \pm 15.7$ \\
\hline $\mathrm{FEV}_{1} / \mathrm{FVC}$ & $2.3-95.9$ & 81.4 & $78.5 \pm 13.0$ \\
\hline DLCO & $7.0-42.0$ & 22.0 & $21.9 \pm 7.1$ \\
\hline DLCO\% & $26.0-140.0$ & 80.0 & $84.0 \pm 21.6$ \\
\hline DLCO/VA & $3.6-18.0$ & 5.2 & $5.7 \pm 2.7$ \\
\hline DLCO/VA\% & $64.0-148.0$ & 104.5 & $103.5 \pm 21.7$ \\
\hline
\end{tabular}

AST - aspartate aminotransferase, ALT - alanine aminotransferase, HDL - high-density lipoprotein, LDL - low-density lipoprotein, Fe - iron, $H B A_{1 c}$ - glycohemoglobin, $T_{3}$ - free triiodothyronine, $T_{4}$ - free thyroxine, TSH - thyroid-stimulating hormone, WBC - white blood cell, $R B C$ - red blood cell, ACE levels - angiotensin converting enzyme levels, FEV - forced expiratory volume in $1 \mathrm{~s}$, FEV $\%$ pred - \% predicted of forced expiratory volume in 1 s, FVC - forced vital capacity, FVC\% pred-\% predicted of forced vital capacity, DLCO-diffusing capacity of the lung for carbon monoxide, DLCO/VA - diffusing capacity of the lung for carbon monoxide divided by the alveolar volume.

cardiac complications due to sarcoidosis. Healthy volunteers were enrolled as a control group. We found that $T_{p}-T_{e} V_{1}, T_{p}-T_{e} V_{2}, T_{p}-T_{e} V_{3}, T_{p}-T_{e} V_{4}$, $T_{p}-T_{e} V_{5}$, and $T_{p}^{p}-T_{e}^{e} V_{6}$ values were significantly higher in patients with sarcoidosis than in controls. We conclude that there was strong evidence that $T_{p}-T_{e}$ intervals were increased in patients with pulmonary sarcoidosis, which suggests that there may be a link between sarcoidosis and ventricular arrhythmias without proven cardiac involvement.

Even though ECG is the key modus in patients, unfortunately it has poor sensitivity; only half of the patients' electrical defects are identified with this method [7]. Ventricular tachycardia is also one of the most frequent arrhythmias noted in cardiac sarcoidosis, and one study demonstrated a $23 \%$ incidence of ventricular tachycardia. The most frequent arrhythmia detected in cardiac sarcoidosis is ventricular tachycardia. A study stated that the incidence of ventricular tachycardia was $23 \%$ [21]. Suzuki et al. detected the sensitivity of cardiac sarcoidosis as $67 \%$ and specificity as $62 \%$ using 24-h Holter when ventricular ectopic beats numbered more than 100/day [22]. Although some studies have reported more than two-fold female dominance, the female/male ratio in other studies has been found between 1 and 1.8 [4, 5, 23-25]. As we showed, in our study the female/male ratio was 1.75 . The study group comprised middle-aged patients, and that same finding has been reported 

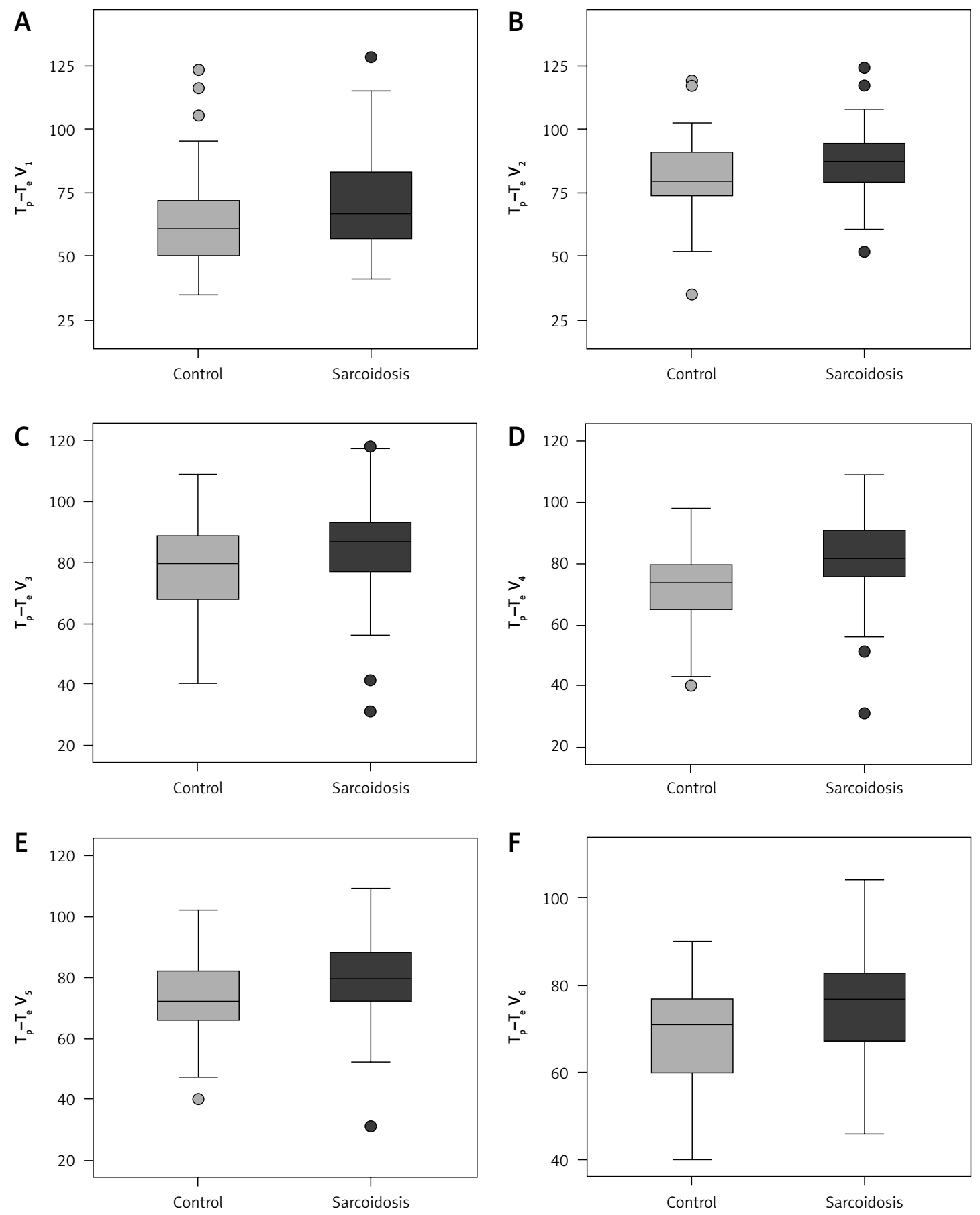

Figure 2. Comparative chart of $\mathrm{T}_{\mathrm{p}}-\mathrm{T}_{\mathrm{e}}$ values of the sarcoidosis and control group

previously in the Turkish population $[1,2,5]$. It was correlated with pulmonary symptoms presented in the Turkish population [5].

Previous studies have stated that continuation of the $T_{p}-T_{e}$ interval is related with increased mortality in Brugada syndrome, long QT syndrome, hypertrophic cardiomyopathy, and in patients with myocardial infarction [26]. Hence, $T_{p}-T_{e}$ interval is a novel parameter for prediction of arrhythmogenic events. The difference between the ends of the shortest and the longest periods of ventricular repolarisation is represented by the $T_{p}-T_{e}$ interval $[27,28]$. Granulomas and the development of ventricular aneurysms supply a substrate for VT and ventricular fibrillation. An abnormal mechanical stimulation of the receptors in the myocardial wall with an increased reflex of the sympathetic activity may be caused by cardiac sarcoidosis with a change of the normal kinetics of the area of the heart that is involved. Sarcoid granulomas are able to develop a centre for automaticity or develop reentrant arrhythmia. Consequently, these 
Table II. The interval from the peak to the end of the electrocardiographic T wave (ms) with cut-off levels

\begin{tabular}{|c|c|c|c|}
\hline Variable & AUC & $\begin{array}{c}95 \% \\
\text { Confidence } \\
\text { interval }\end{array}$ & $P$-value \\
\hline$T_{p}-T_{e} V_{1}$ & 0.628 & $0.518-0.738$ & 0.027 \\
\hline Cut-off value 65 & 0.618 & $0.508-0.727$ & 0.042 \\
\hline$T_{p}-T_{e} V_{2}$ & 0.618 & $0.505-0.731$ & 0.041 \\
\hline Cut-off value 76 & 0.637 & $0.526-0.748$ & 0.018 \\
\hline$T_{p}-T_{e} V_{3}$ & 0.621 & $0.509-0.733$ & 0.036 \\
\hline Cut-off value 76 & 0.628 & $0.517-0.740$ & 0.026 \\
\hline$T_{p}-T_{e} V_{4}$ & 0.722 & $0.623-0.821$ & 0.000 \\
\hline Cut-off value 70 & 0.685 & $0.577-0.793$ & 0.001 \\
\hline$T_{p}-T_{e} V_{5}$ & 0.659 & $0.551-0.766$ & 0.006 \\
\hline Cut-off value 71 & 0.651 & $0.542-0.760$ & 0.009 \\
\hline$T_{p}-T_{e} V_{6}$ & 0.682 & $0.579-0.785$ & 0.002 \\
\hline Cut-off value 71 & 0.617 & $0.507-0.728$ & 0.042 \\
\hline
\end{tabular}

parameters can be regarded as risk factors for sudden death in patients with cardiac sarcoidosis. ECG analyses can be used to separate patients according to risk factors.

Another factor that is associated with ventricular arrhythmias and sudden cardiac death is the transmural dispersion of repolarisation, which is calculated as the interval between the peak
Table III. Comparison of $T_{p}-T_{e}$ interval between the sarcoidosis and control groups

\begin{tabular}{|lccc|}
\hline Variable & $\begin{array}{c}\text { Control group, } \\
\text { mean } \pm \mathrm{SD}\end{array}$ & $\begin{array}{c}\text { Sarcoidosis } \\
\text { group, } \\
\text { mean } \pm \mathrm{SD}\end{array}$ & \\
\hline $\mathrm{T}_{\mathrm{p}}-\mathrm{T}_{\mathrm{e}} \mathrm{V}_{1}[\mathrm{~ms}]$ & $64.0 \pm 19.3$ & $71.7 \pm 20.2$ & 0.021 \\
\hline $\mathrm{T}_{\mathrm{p}}-\mathrm{T}_{\mathrm{e}} \mathrm{V}_{2}[\mathrm{~ms}]$ & $80.1 \pm 16.2$ & $86.1 \pm 13.3$ & 0.018 \\
\hline $\mathrm{T}_{\mathrm{p}}-\mathrm{T}_{\mathrm{e}} \mathrm{V}_{3}[\mathrm{~ms}]$ & $78.7 \pm 15.5$ & $83.9 \pm 16.5$ & 0.027 \\
\hline $\mathrm{T}_{\mathrm{p}}-\mathrm{T}_{\mathrm{e}} \mathrm{V}_{4}[\mathrm{~ms}]$ & $71.6 \pm 12.8$ & $82.1 \pm 13.2$ & 0.000 \\
\hline $\mathrm{T}_{\mathrm{p}}-\mathrm{T}_{\mathrm{e}} \mathrm{V}_{5}[\mathrm{~ms}]$ & $73.5 \pm 12.5$ & $80.1 \pm 13.4$ & 0.002 \\
\hline $\mathrm{T}_{\mathrm{p}}-\mathrm{T}_{\mathrm{e}} \mathrm{V}_{6}[\mathrm{~ms}]$ & $68.5 \pm 12.2$ & $76.5 \pm 12.8$ & 0.001 \\
\hline
\end{tabular}

$T_{p}-T_{e}$ - the interval from the peak to the end of the electrocardiographic $T$ wave in $m s$, mean $\pm S D-$ mean \pm standard deviation.

Table IV. Comparison of $T_{p}-T_{e}$ intervals according to the presence of extra-pulmonary involvement in different stages of sarcoidosis

\begin{tabular}{|lccc|}
\hline Variable & $\begin{array}{c}\text { Extra- } \\
\text { pulmonary } \\
\text { involvement }(-) \\
\text { Mean } \pm \mathrm{SD}\end{array}$ & $\begin{array}{c}\text { Extra- } \\
\text { pulmonary } \\
\text { involvement (+) } \\
\text { Mean } \pm \mathrm{SD}\end{array}$ & P-value \\
\hline $\mathrm{T}_{\mathrm{p}}-\mathrm{T}_{\mathrm{e}} \mathrm{V}_{1}[\mathrm{~ms}]$ & $71.8 \pm 20.4$ & $65.3 \pm 13.3$ & 0.62 \\
\hline $\mathrm{T}_{\mathrm{p}}-\mathrm{T}_{\mathrm{e}} \mathrm{V}_{2}[\mathrm{~ms}]$ & $85.6 \pm 12.9$ & $89.4 \pm 17.1$ & 0.90 \\
\hline $\mathrm{T}_{\mathrm{p}}-\mathrm{T}_{\mathrm{e}} \mathrm{V}_{3}[\mathrm{~ms}]$ & $83.7 \pm 17.4$ & $85.3 \pm 7.0$ & 0.95 \\
\hline $\mathrm{T}_{\mathrm{p}}-\mathrm{T}_{\mathrm{e}} \mathrm{V}_{4}[\mathrm{~ms}]$ & $81.0 \pm 13.0$ & $88.1 \pm 13.0$ & 0.25 \\
\hline $\mathrm{T}_{\mathrm{p}}-\mathrm{T}_{\mathrm{e}} \mathrm{V}_{5}[\mathrm{~ms}]$ & $79.7 \pm 14.2$ & $83.0 \pm 5.5$ & 0.35 \\
\hline $\mathrm{T}_{\mathrm{p}}-\mathrm{T}_{\mathrm{e}} \mathrm{V}_{6}[\mathrm{~ms}]$ & $76.3 \pm 13.1$ & $78.5 \pm 11.4$ & 0.63 \\
\hline
\end{tabular}

Mean $\pm S D-$ mean \pm standard deviation, $T_{p}-T_{e}$ donates $T$ wave peak to end interval in $\mathrm{ms}$.

Table V. Correlations between T-wave peak to end interval of chest derivations and pulmonary function tests

\begin{tabular}{|c|c|c|c|c|c|c|c|c|}
\hline Correlations & & $\mathrm{FEV}_{1} \%$ & FVC\% & $\mathrm{FEV}_{1} / \mathrm{FVC}$ & DLCO & DLCO\% & DLCO/VA & DLCO/VA\% \\
\hline \multirow[t]{2}{*}{$T_{p}-T_{e} V_{1}$} & $\begin{array}{l}\text { Correlation } \\
\text { coefficient }\end{array}$ & -0.23 & -0.29 & -0.08 & 0.15 & -0.05 & -0.01 & 0.14 \\
\hline & $P$-value & 0.05 & 0.01 & 0.49 & 0.26 & 0.67 & 0.91 & 0.34 \\
\hline \multirow[t]{2}{*}{$T_{p}-T_{e} V_{2}$} & $\begin{array}{l}\text { Correlation } \\
\text { coefficient }\end{array}$ & -0.02 & -0.05 & -0.45 & -0.04 & -0.08 & 0.33 & 0.20 \\
\hline & $P$-value & 0.81 & 0.97 & 0.001 & 0.76 & 0.53 & 0.03 & 0.18 \\
\hline \multirow[t]{2}{*}{$T_{p}-T_{e} V_{3}$} & $\begin{array}{l}\text { Correlation } \\
\text { coefficient }\end{array}$ & -0.05 & -0.03 & -0.45 & 0.03 & -0.08 & 0.32 & -0.02 \\
\hline & $P$-value & 0.65 & 0.78 & 0.001 & 0.80 & 0.53 & 0.03 & 0.90 \\
\hline \multirow[t]{2}{*}{$T_{p}-T_{e} V_{4}$} & $\begin{array}{l}\text { Correlation } \\
\text { coefficient }\end{array}$ & 0.04 & -0.01 & -0.02 & 0.001 & -0.11 & 0.49 & 0.15 \\
\hline & $P$-value & 0.72 & 0.90 & 0.84 & 0.99 & 0.40 & 0.001 & 0.31 \\
\hline \multirow[t]{2}{*}{$T_{p}-T_{e} V_{5}$} & $\begin{array}{l}\text { Correlation } \\
\text { coefficient }\end{array}$ & -0.08 & -0.02 & -0.06 & 0.04 & -0.02 & 0.12 & -0.08 \\
\hline & $P$-value & 0.50 & 0.86 & 0.60 & 0.76 & 0.88 & 0.41 & 0.57 \\
\hline \multirow[t]{2}{*}{$T_{p}-T_{e} V_{6}$} & $\begin{array}{l}\text { Correlation } \\
\text { coefficient }\end{array}$ & -0.04 & -0.05 & -0.06 & 0.12 & 0.07 & 0.22 & 0.15 \\
\hline & $P$-value & 0.72 & 0.64 & 0.58 & 0.38 & 0.60 & 0.14 & 0.30 \\
\hline
\end{tabular}

$T-T$ - T-wave peak to end interval, FEV \% - percentage of predicted forced expiratory volume in $1 \mathrm{~s}$, FVC\% - percentage of predicted of forced vital capacity, DLCO - diffusing capacity of the lung for carbon monoxide, DLCONVA - diffusing capacity of the lung for carbon monoxide divided by the alveolar volume, DLCONA\% - percentage of predicted of diffusing capacity of the lung for carbon monoxide divided by the alveolar volume. 
Table VI. The best cut-off values of $T_{p}-T_{e}$ intervals to predict sarcoidosis

\begin{tabular}{|lcccc|}
\hline Correlations & Cut-off value & Sensitivity & Specificity & $P$-value \\
\hline$T_{p}-T_{e} V_{1}[\mathrm{~ms}]$ & 50.5 & 0.81 & 0.64 & 0.04 \\
\hline$T_{p}-T_{e} V_{2}[\mathrm{~ms}]$ & 65.5 & 0.95 & 0.80 & 0.02 \\
\hline$T_{p}-T_{e} V_{3}[\mathrm{~ms}]$ & 64.5 & 0.90 & 0.80 & 0.02 \\
\hline$T_{p}-T_{e} V_{4}[\mathrm{~ms}]$ & 64 & 0.95 & 0.75 & $<0.001$ \\
\hline$T_{p}-T_{e} V_{5}[\mathrm{~ms}]$ & 65.5 & 0.91 & 0.79 & $<0.001$ \\
\hline$T_{p}-T_{e} V_{6}[\mathrm{~ms}]$ & 60.5 & 0.95 & 0.73 & 0.001 \\
\hline
\end{tabular}

$T_{p}-T_{e}$-the interval from the peak to the end of the electrocardiographic $T$ wave of leads in $m s$.

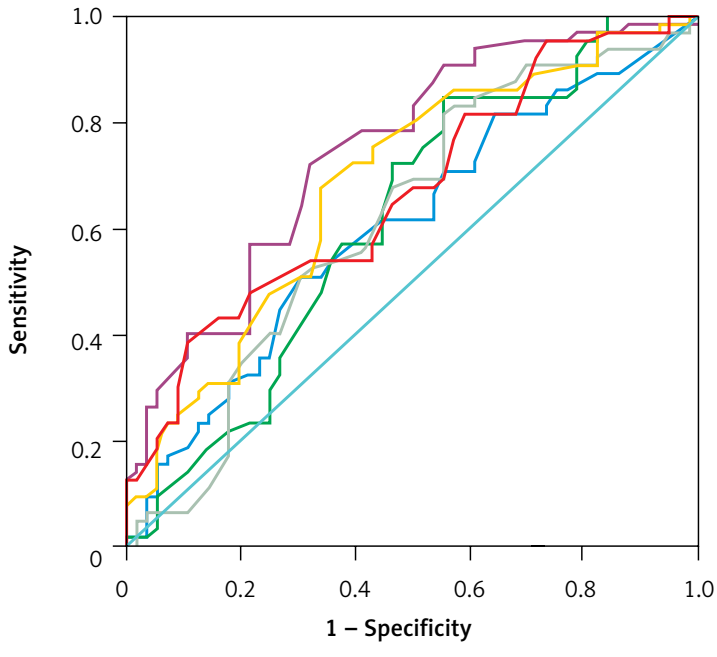

Diagonal segments are produced by ties.

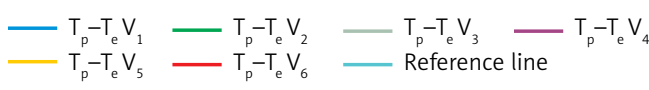

Figure 3. ROC curve analysis of $T_{p}-T_{e}$ intervals to predict sarcoidosis

and the end of the $T$ wave on electrocardiogram $[14,15]$. Electro-physiologic property changes in pathologic LVH may be related with myocardial architecture deformities such as myocardial disarray, interstitial fibrosis, and inhomogeneous cardiac myocyte hypertrophy $[1,29,30]$.

On the other hand, the relation between the QT duration and sudden cardiac death (SCD) in the general population is relatively week. An association between prolongation of the T-wave peak to $T_{p}-T_{e}$ and SCD has been found recently in a general population sample [31]. However, $T_{p}-T_{e}$ was shorter in patients who died from any cause compared with survivors. Moreover, it was not predictive of death in multivariable analyses when $T_{p}-T_{e}$ was measured in male patients with cardiovascular disease and the measurement points were averaged in leads $V_{4}$ to $V_{6}$ [32]. In a recent case-control study, $\mathrm{T}_{\mathrm{p}}-\mathrm{T}_{\mathrm{e}}$ prolongation measured in lead $\mathrm{V}_{5}$ was associated with SCD in a general population sample [31].

Increased inflammatory activity is stated as being related with the pathogenesis of cardiovascular diseases and arrhythmia in these patients $[32,33]$. Ventricular arrhythmia is thought to be triggered by increased dispersion of repolarisa- tion and disturbance of the normal orderly pattern of ventricular recovery. Recently, the $T_{p}-T_{e}$ interval has arisen as a novel electrocardiographic marker of increased diffusion of ventricular repolarisation [34].

This study has some limitations. First of all is a retrospective method of study in which patients could not be followed up prospectively for future arrhythmic events. Secondly, we had a small sample size. We did not observe any arrhythmias in the study population. The study population could not be examined in detail to show the arrhythmia because the study was designed retrospectively. Measurement of the QT interval and its dispersion was not standardised. Another limitation is that the patients with pulmonary sarcoidosis were not screened for cardiac involvement with any additional cardiac imaging modalities such as cardiac magnetic resonance or echocardiography. In published studies, death due to cardiac reasons in sarcoidosis patients has been reported in many cases. The presence of sustained ventricular tachycardia (VT), severity of heart failure, and LV end-diastolic diameter predict sudden death [35]. Currently we have very good predictive markers for ventricular arrhythmias and sudden cardiac death; late gadolinium enhancement on cardiac MRI and focal uptake on cardiac PET has also been associated with higher risk of death or VT [36-38]. Greulich et al. showed that late gadolinium enhancement on cardiac MRI predicts death and cardiac events. Defining prognostic factors is important to guide treatment in cardiac sarcoidosis [36].

However, in light of our study, we can conclude that there is a link between $T_{p}-T_{e}$ interval and ventricular arrhythmias in sarcoidosis.

In conclusion, these results contribute to the pathophysiologic mechanisms of the high prevalence of ventricular arrhythmias and cardiovascular mortality risk by revealing increased ventricular repolarisation heterogeneity in patients with sarcoidosis. The relevance of this finding to clinical outcomes and the clinical usefulness of this simple bedside parameter remains to be determined with further studies. Attention is drawn to the importance of ECG, which is a useful, simple, nonin- 
vasive, broadly accessible, easily repeatable/conducted, and affordable tool in the differentiation of patients with and without cardiac involvement in sarcoidosis. It may be used to screen for occult cardiac involvement in pulmonary sarcoidosis after further studies involving larger populations.

\section{Acknowledgments}

We would like to thank David F. Chapman for English language editing, and Ertan Koç for statistical analysis.

\section{Conflict of interest}

The authors declare no conflict of interest.

\section{References}

1. The European Respiratory Society (ERS) and the World Association of Sarcoidosis and Other Granulomatous Disorders (WASOG) adopted by the ATS Board of Directors and by the ERS Executive Committee Statement on sarcoidosis Joint Statement of the American Thoracic Society (ATS). Am J Respir Crit Care Med 1999; 160: 736-55.

2. Baughman RP, Teirstein AS, Judson MA, et al. Case Control Etiologic Study of Sarcoidosis (ACCESS) research group. Am J Respir Crit Care Med 2001; 16: 1885-9.

3. Sekhri V, Sanal S, DeLorenzo L, Aronow W, Maguire G. Cardiac sarcoidosis: a comprehensive review. Arch Med Sci 2011; 7: 546-54.

4. Pietinalho A, Hiraga Y, Hosoda Y, Lofroos AB, Yamaguchi M, Selroos $\mathrm{O}$. The frequency of sarcoidosis in Finland and Hokkaido, Japan: a comparative epidemiological study. Sarcoidosis 1995; 12: 61-7.

5. Kıter G, Müsellim B, Cetinkaya E, Türker H, Kunt Uzaslan AE, Yenturk E. Clinical presentations and diagnostic workup in sarcoidosis: a series of Turkish cases (clinics and diagnosis of sarcoidosis). Tuberk Toraks 2011; 59: 248-58.

6. Birniel D, Kandolin R, Nery PB, Kupari M. Cardiac manifestations of sarcoidosis: diagnosis and management. Eur Heart J 2017; 38: 2663-70.

7. Silverman K, Hutchins G, Bulkley B. Cardiac sarcoid: a clinicopathologic study of 84 unselected patients with systemic sarcoidosis. Circulation 1978; 58: 1204-11.

8. Iwai K, Tachibana T, Takemura T, Matsui Y, Kitaichi M, Kawabata Y. Pathological studies on sarcoidosis autopsy. I. Epidemiological features of 320 cases in Japan. Acta Pathol Jpn 1993; 43: 372-76.

9. Perry A, Vuitch F. Causes of death in patients with sarcoidosis. A morphologic study of 38 autopsies with clinicopathologic correlations. Arch Pathol Lab Med 1995; 119: 167-72.

10. Roberts W, McAllister H, Ferrans V. Sarcoidosis of the heart: a clinicopathologic study of 35 necropsy patients and review of 78 previously described necropsy patients. Am J Med 1977; 63: 86-108.

11. Silverman K, Hutchins G, Buckley B. Cardiac sarcoid: a clinicopathologic study of 84 unselected patients with systemic sarcoidosis. Circulation 1978; 58: 1204-11.

12. Kors J, Ritsema van Eck H, van Herpen G. The meaning of the Tp-Te interval and its diagnostic value. J Electrocardiol 2008; 41: 575-80.

13. Antzelevitch C, Sicouri S, Di Diego JM, Burashnikov A, Viskin S, Shimizu W. Does Tpeak-Tend provide an in- dex of transmural dispersion of repolarization? Heart Rhythm 2007; 4: 1114-6.

14. Castro Hevia J, Antzelevitch C, Tornés Bárzaga F, Dorantes Sánchez M, Dorticós Balea F, Zayas Molina R. Tpeak-Tend and Tpeak-Tend dispersion as risk factors for ventricular tachycardia/ventricular fibrillation in patients with the Brugada syndrome. J Am Coll Cardiol 2006; 47: 1828-34.

15. Smetana P, Schmidt A, Zabel M, Hnatkova K, Franz M, Huber K. Assessment of repolarization heterogeneity for prediction of mortality in cardiovascular disease: peak to the end of the T wave interval and nondipolar repolarization components. J Electrocardiol 2011; 44: 301-8.

16. Erikssen G, Liestøl K, Gullestad L, Haugaa KH, Bendz B, Amlie JP. The terminal part of the QT interval ( $T$ peak to $T$ end): a predictor of mortality after acute myocardial infarction. Ann Noninvasive Electrocardiol 2012; 17: 85-94.

17. Hunninghake GW, Costabel U, Ando M, Baughman R, Cordier JF, Bois R. ATS/ERS/WASOG statement on sarcoidosis. American Thoracic Society/European Respiratory Society/World Association of Sarcoidosis and other Granulomatous Disorders. Sarcoidosis Vasc Diffuse Lung Dis 1999; 16: 149-73.

18. Hanci V, Yurtlu S, Aydin M, Bilir S, Erdoğan G, Okyay RD. Preoperative abnormal $P$ and QTc dispersion intervals in patients with metabolic syndrome. Anesth Analg 2011; 112: 824-7.

19. Antzelevitchc C, Sicouri S, Di Diego JM, Burashnikov A, Viskin S, Shimizu W. Does Tpeak-Tend provide an index of transmural dispersion of repolarization? Heart Rhythm 2007; 4: 1114-6.

20. Panikkath R, Reinier K, Uy-Evanado A, Teodorescu C, Hattenhauer J, Mariani R. Prolonged T peak-to-T end interval on the resting ECG is associated with increased risk of sudden cardiac death. Circ Arrhythm Electrophysiol 2011; 4: 441-7.

21. Furushima $H$, Chinushi $M$, Sugiura $H$, Kasai $H$, Washizuka T, Aizawa Y. Ventricular tachyarrhythmia associated with cardiac sarcoidosis: its mechanisms and outcome. Clin Cardiol 2004; 27: 217-22.

22. Suzuki T, Kanda T, Kubota S, Imai S, Murata K. Holter monitoring as a noninvasive indicator of cardiac involvement in sarcoidosis. Chest 1994; 106: 1021-4.

23. Mihailovic-Vucinic V, Zugic V, Videnovic-Ivanov J. New observations on pulmonary function changes in sarcoidosis. Curr Opin Pulm Med 2003; 9: 436-41.

24. Judson MA, Thompson BW, Rabin DL, Steimel J, Knattereud GL, Lackland DT; ACCESS Research Group. The diagnostic pathway to sarcoidosis. Chest 2003; 123: 406-12.

25. Loddenkemper R, Kloppenborg A, Schoenfeld N, Grosser H, Costabel U. Clinical findings in 715 patients with newly detected pulmonary sarcoidosis: results of a cooperative study in former West Germany and Switzerland. WATL Study Group: Wissenschaftliche Arbeitsgemeinschaft für die Therapie von Lungenk-rankheiten. Sarcoidosis Vasc Diffuse Lung Dis 1998; 15: 178-82.

26. Zhao X, Xie Z, Chu Y, Yang L, Xu W, Yang X. Association between Tp-e/QT ratio and prognosis in patients undergoing primary percutaneous coronary intervention for ST-segment elevation myocardial infarction. Clin Cardiol 2012; 35: 559-64.

27. Antzelevitch C. T peak-Tend interval as an index of transmural dispersion of repolarization. Eur J Clin Invest 2001; 31: 555-7.

28. Antzelevitch C. M cells in the human heart. Circ Res 2010; 106: 815-7. 
29. Haider AW, Larson MG, Benjamin EJ, Levy D. Increased left ventricular mass and hypertrophy are associated with increased risk for sudden death. J Am Coll Cardiol 1998; 32: 1454-9.

30. McIntyre H, Fry CH. Abnormal action potential conduction in isolated human hypertrophied left ventricular myocardium. J Cardiovasc Electrophysiol 1997; 8: 887-94.

31. Panikkath R, Reinier K, Uy-Evanado A, Teodorescu C, Hattenhauer J, Mariani R. Prolonged Tpeak-to-tend interval on the resting ECG is associated with increased risk of sudden cardiac death. Circ Arrhythm Electrophysiol 2011; 4: 441-7.

32. Demir M. The relationship between neutrophil lymphocyte ratio and non-dipper hypertension. Clin Exp Hypertens 2013; 35: 570-3.

33. Watanabe N, Kobayashi Y, Tanno K, Miyoshi F, Asano T, Kawamura M. Transmural dispersion of repolarization and ventricular tachyarrhythmias. J Electrocardiol 2004; 37: 191-200

34. Kors JA, Ritsema van Eck HJ, van Herpen G. The meaning of the Tp-Te interval and its diagnostic value. J Electrocardiol 2008; 41: 575-80.

35. Yazaki $Y$, Isobe $M$, Hiroe $M$, et al. Prognostic determinants of long-term survival in Japanese patients with cardiac sarcoidosis treated with prednisone. Am J Cardiol 2001; 88: 1006-10.

36. Greulich S, Deluigi CC, Gloekler S, et al. CMR imaging predicts death and other adverse events in suspected cardiac sarcoidosis. JACC Cardiovasc Imaging 2013; 6: 501-11.

37. Shafee MA, Fukuda K, Wakayama Y, et al. Delayed enhancement on cardiac magnetic resonance imaging is a poor prognostic factor in patients with cardiac sarcoidosis. J Cardiol 2012; 60: 448-53.

38. Blankstein R, Osborne M, Naya M, et al. Cardiac positron emission tomography enhances prognostic assessments of patients with suspected cardiac sarcoidosis. J Am Coll Cardiol 2014; 63: 329-36. 